DE

M E D I C I N A

T R O P I C A L

$\mathrm{DE}$

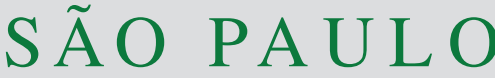

JOURNAL OF THE SÃO PAULO INSTITUTE OF TROPICAL MEDICINE

${ }^{1}$ Pontifícia Universidade Católica do Rio Grande do Sul, Laboratório de Imunologia e Microbiologia, Porto Alegre, Rio Grande do Sul, Brazil

${ }^{2}$ Secretaria Estadual de Saúde, Centro Estadual de Vigilância em Saúde, Laboratório Central de Saúde Pública, Porto Alegre, Rio Grande do Sul, Brazil

${ }^{3}$ Embrapa Suínos e Aves, Concórdia, Santa Catarina, Brazil

Correspondence to: Marjo Cadó Bessa Pontifícia Universidade Católica do Rio Grande do Sul, Laboratório de Imunologia e Microbiologia, Av. Ipiranga, 6681, prédio 12, sala 201, bloco D, CEP 90619-900, Porto Alegre, RS, Brazil

E-mail: marjo.bessa@pucrs.br

Received: 3 August 2020

Accepted: 28 October 2020

\section{Survey of Campylobacter in foods implicated in foodborne diseases in Southern Brazil}

\author{
Marjo Cadó Bessa ${ }^{\circledR 1}$, Simone Haas ${ }^{2}$, Rosane Campanher Ramos ${ }^{2}$, Raquel \\ Rocha $^{2}$, Daiane Voss-Rech ${ }^{3}$, Raquel Rebelatto ${ }^{3}$, Sabrina Castilho Duarte $^{3}$, \\ Arlei Coldebella ${ }^{3}$, Clarissa Silveira Luiz Vaz ${ }^{3}$
}

\section{ABSTRACT}

Campylobacter is not routinely tested in foodborne disease investigations in Brazil. Here, we studied the occurrence of Campylobacter among other food-related bacteria commonly found in foodborne disease outbreaks reported in Rio Grande do Sul State, Southern Brazil. Seventy-two food samples were analyzed by using culture-based detection methods during the 18-month investigation of 36 foodborne disease outbreaks. The sampled foods from the foodborne disease outbreaks were all negative for Campylobacter. However, at least one of other routinely investigated foodborne-related bacteria was detected in $29.17 \%$ (21/72) of the samples. Taken together, these results suggest the need to monitor Campylobacter in foodborne diseases to detect sporadic cases caused by Campylobacter that might go unnoticed in Rio Grande do Sul.

KEYWORDS: Campylobacter. Food safety. Outbreak.

\section{INTRODUCTION}

Campylobacter is the most prevalent pathogen in foodborne gastroenteritis infections in developed countries ${ }^{1,2}$. Campylobacter jejuni is mostly associated with human infections and is more frequent in laboratory-confirmed cases, followed by C. coli and C. lari $^{1}$. Epidemiological studies have demonstrated that campylobacteriosis primarily results from the consumption or mishandling of contaminated food of animal origin, especially from chicken ${ }^{1,3}$.

In Brazil, Campylobacter has been reported in chicken meat and other foods of animal origin ${ }^{3,4}$, as well as in human feces ${ }^{4}$. However, only eight foodborne disease outbreaks involving Campylobacter spp. were reported to the Brazilian Ministry of Health among the approximately 14,000 outbreaks occurring in the period 2000 to $2019^{5}$. From 2009 to 2018, 6,903 foodborne disease outbreaks were reported in Brazil, and Escherichia coli (24.0\%), Salmonella spp. (11.2\%), and Staphylococcus aureus $(9.5 \%)$ were the most frequently identified microorganisms in laboratory-confirmed cases ${ }^{6}$. The Central Public Health Laboratories (LACENs) network is structured to provide, among other attributes, the laboratory analyses to support the Brazilian epidemiological surveillance system for foodborne diseases. However, Campylobacter is not routinely tested in foodborne disease investigations. Hence, the incidence of foodborne campylobacteriosis may be underestimated in Brazil. This study aimed to analyze the occurrence of Campylobacter in foods implicated in foodborne diseases reported in Rio Grande do Sul State, Southern Brazil. 


\section{MATERIALS AND METHODS}

\section{Food samples}

In the period from March 2015 to September 2016, the LACEN-RS (Porto Alegre, Rio Grande do Sul State) provided 72 subsamples of foodborne diseaseassociated foods for Campylobacter analysis. Samples were of dairy products; sausages, eggs, meals prepared with eggs, chicken, pork, beef and fish, and foods of other origins. Samples were collected by the municipal health surveillance services as part of the investigation of 36 foodborne disease outbreaks to determine their etiological agents. These outbreaks comprised cases of a similar disease with similar incubation period distribution, deriving from common foods sources, and patients presented with at least one of the following symptoms: nausea; vomiting; stomach cramps; diarrhea and headache. The foods came from nine of the 19 Regional Health Coordinating Units (CRS) in Rio Grande do Sul, covering different municipalities (Figure 1). Samples were transported chilled to the laboratory and analyzed within $24 \mathrm{~h}$. A descriptive analysis was carried out to determine the relationship between the categories of foods analyzed, the bacteria identified and the CRS of origin.

\section{Routine bacteriological analysis}

Foods were submitted to conventional bacteriological analyses at LACEN-RS to detect pathogenic (Salmonella spp., coagulase-positive staphylococci, Listeria monocytogenes, Bacillus cereus and sulphite-reducing Clostridium at $46^{\circ} \mathrm{C}$ ) and non-pathogenic (Escherichia coli) bacteria ${ }^{7}$. Samples were tested according to the clinical presentation and food microbiological criteria established in Brazil ${ }^{8}$.

\section{Qualitative analysis of thermotolerant Campylobacter}

Subsamples of either cooked or raw foods were subjected to Campylobacter qualitative analysis using a protocol applicable to products for human consumption ${ }^{9}$. Briefly, the samples were homogenized in Bolton broth (Fluka, Darmstadt, Hesse, Germany) and incubated in a microaerobic atmosphere $\left(5 \% \mathrm{O}_{2}, 10 \% \mathrm{CO}_{2}\right.$, with balance in $\left.\mathrm{N}_{2}\right)$ at $37^{\circ} \mathrm{C}$ for $4 \mathrm{~h}$, followed by incubation at $41.5^{\circ} \mathrm{C}\left( \pm 1{ }^{\circ} \mathrm{C}\right)$ for $44 \mathrm{~h}$ $( \pm 4 \mathrm{~h})$. Enriched samples were plated on modified Charcoal Cefoperazone Deoxycholate agar (mCCD, Fluka, Darmstadt, Hesse, Germany) and on Preston agar (Fluka, Darmstadt, Hesse, Germany), and incubated in microaerobic atmosphere at $41.5{ }^{\circ} \mathrm{C}\left( \pm 1{ }^{\circ} \mathrm{C}\right)$ for $44 \mathrm{~h}( \pm 4 \mathrm{~h})$. Typical or putative Campylobacter colonies were subcultured on blood agar base $n^{\circ} .2$ (Fluka, Darmstadt, Hesse, Germany) to be further analyzed by Gram staining, motility, microaerobic growth at $25^{\circ} \mathrm{C}$, aerobic growth at $41.5^{\circ} \mathrm{C}$ and oxidase. C. jejuni (BRM 34342) and $C$. coli (BRM 34343) from the microbial culture collection (CMISEA) of Embrapa (Empresa Brasileira de Pesquisa Agropecuaria) Swine and Poultry were used as controls strains.

\section{RESULTS AND DISCUSSION}

In the period studied, the most common analyzed food samples were from the category of beef meals $(14 / 72,19.44 \%)$, followed by fish meals $(11 / 72,15.28 \%)$ and sausages $(11 / 72,15.28 \%)$. Samples were primarily collected by the $2^{\text {nd }}$ CRS $(27 / 72,37.50 \%)$ and the $5^{\text {th }}$

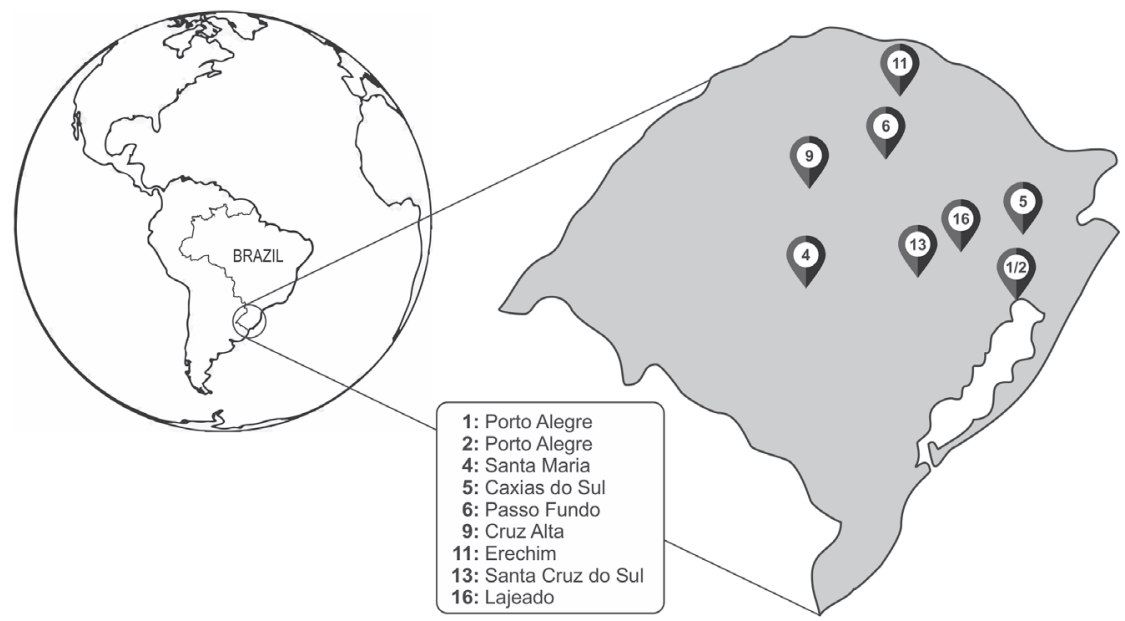

Figure 1 - Provenance (number of samples/total analyzed number) of the foods according to the Regional Health Coordinating Unit (CRS) in Rio Grande do Sul, Southern Brazil. 1: $1^{\text {st }}$ CRS Porto Alegre (6/72); $2: 2^{\text {nd }}$ CRS Porto Alegre (27/72); 4: $4^{\text {th }}$ CRS Santa Maria (1/72); 5: $5^{\text {th }}$ CRS Caxias do Sul $(23 / 72) ; 6: 6^{\text {th }}$ CRS Passo Fundo (7/72); 9: $9^{\text {th }}$ CRS Cruz Alta $(1 / 72) ; 11: 11^{\text {th }}$ CRS Erechim (4/72); 13: $13^{\text {th }}$ CRS Santa Cruz do Sul (2/72); 16: $16^{\text {th }}$ CRS Lajeado (1/72). 
CRS $(23 / 72,31.94 \%)$. Contrary to the known high rates of Campylobacter in chicken and poultry samples ${ }^{3,4}$ in Brazil, thermotolerant Campylobacter species were not detected in the foods analyzed in this study. Differences in campylobacteriosis incidence vary among countries or regions within the same country due to the sensitivity of laboratory procedures, population or surveillance bias ${ }^{10}$.

Notably, campylobacteriosis generally occurs as sporadic cases ${ }^{1}$. Sporadic campylobacteriosis might be part of the underreported foodborne diseases in Brazil as they are seldom identified. In the USA, Campylobacter accounts for the highest incidence of bacterial foodborne infections per 100,000 inhabitants $^{2}$. However, when considering bacterial foodborne disease outbreaks, it is the third most common (4\%), after Salmonella spp. (19\%) and C. perfringens $(6 \%)^{11}$. The campylobacteriosis foodborne outbreaks in Brazil occurred in 2001, 2003, 2005, 2014, 2016 and 2019 and involved fruits, desserts, water, mixed foods, milk, dairy products and poultry meat. In total 299 people fell ill ${ }^{5}$.

On the other hand, the competing microbiota could have hindered the detection of low levels of Campylobacter in the foods, since a relatively low dose (500 CFU) is able to cause intestinal colonization and trigger acute enteritis ${ }^{12}$. Campylobacter-negative samples may reflect the effect of several intrinsic and extrinsic factors to which the foods were exposed to. For example, Campylobacter cells can suffer sublethal injuries caused by oxidative stress $^{13}$, acidic conditions ${ }^{14}$, low temperature ${ }^{15}$ or excessive use of disinfectants and preservative additives ${ }^{16}$, which might trigger the viable but non-culturable (VBNC) state. It has been hypothesized that VBNC Campylobacter cells may proliferate in the human intestine and cause infection ${ }^{17-19}$. Despite the presence of VBNC forms that were not evaluated in this study and the lack of evidence that their presence in foods could trigger campylobacteriosis in consumers, the public health risk should not be ignored.
At least one of the other pathogenic and nonpathogenic bacteria tested was detected in $29.17 \%$ (21/72) of the analyzed samples (Figure 2), involved in 17 of the 36 investigated outbreaks. Five samples presented contamination by more than one bacterial agent (data not shown). Among the microorganisms that are not normally harmful but may be used as an indirect indicator of health hazard in food, non-pathogenic E. coli was detected in $20.83 \%$ of the analyzed samples (15/72, Figure 2). E. coli was the second most frequently reported microorganism in foodborne disease outbreak investigations in Brazil from 2000 to $2019^{5}$. Such a number includes non-pathogenic E. coli and Shiga toxin-producing E. coli ${ }^{5}$. Most of the samples evaluated in this study $(51 / 72,70.83 \%)$ were negative for the routinely tested bacteria. Other foodborne microorganisms, such as zoonotic viruses, may be related to outbreak-associated foodborne diseases, which, however, were not focused on in this study. Similar frequency of food-related bacteria has been reported in foodborne disease outbreaks between 2009 and 2018 in Brazil, whose etiological agent was laboratory-confirmed in approximately $30 \%$ of the cases ${ }^{5}$. Despite the number of cases in which the involved food was not identified, the closure of foodborne disease outbreaks investigations has been mostly achieved based on epidemiological criteria without considering the laboratory result ${ }^{20}$. Moreover, the attribution of outbreaks to any of the agents detected during this study depends on the establishment of a clear epidemiological relationship.

In conclusion, the foods analyzed in the studied period tested negative for thermotolerant Campylobacter. Nevertheless, other bacteria were laboratory-confirmed in $29.17 \%$ of the samples. Taken together, the results suggest the need to monitor Campylobacter in foodborne diseases to detect sporadic Campylobacter-associated cases that might go unnoticed in Rio Grande do Sul.

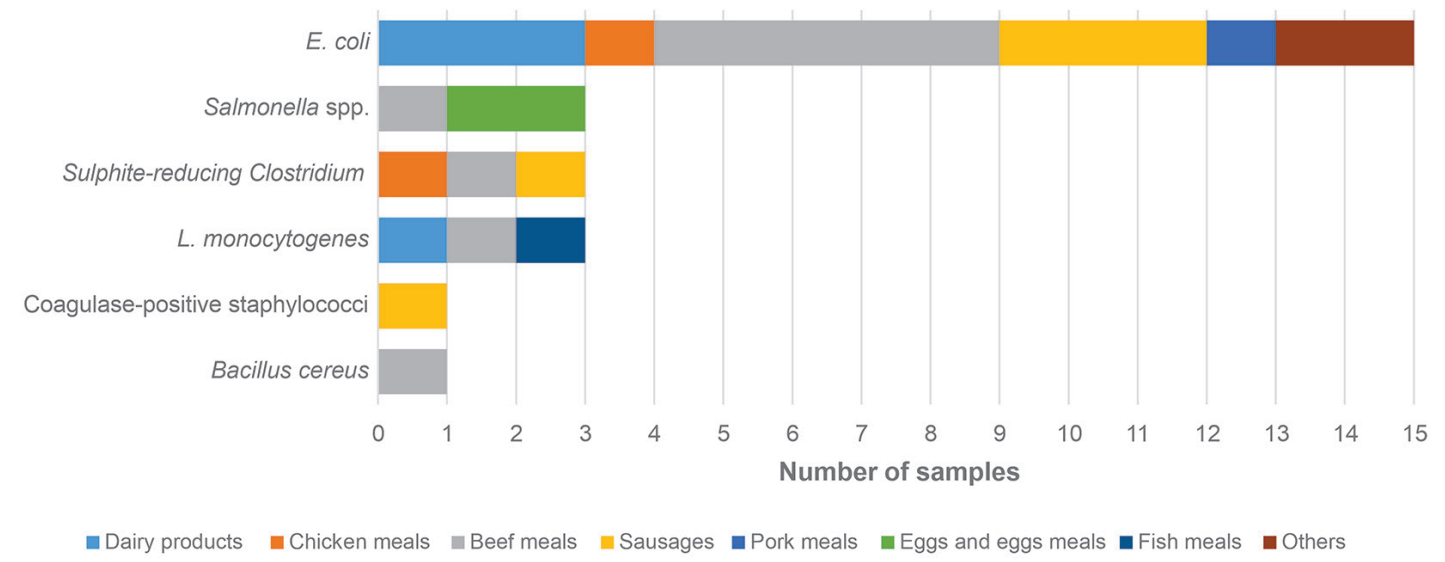

Figure 2 - Distribution of the pathogenic and non-pathogenic bacteria identified in the foods involved in foodborne disease outbreaks in Rio Grande do Sul, Southern Brazil, in the period 2015-2016. 


\section{ACKNOWLEDGMENTS}

We thank LACEN/CEVS/SES-RS and its technical team who has assisted this study, and PUCRS for the research grant to MCB. This work was supported by the National Council for Scientific and Technological Development CNPq (grant $\mathrm{N}^{\circ} 477431 / 2013-5$ ).

\section{AUTHORS' CONTRIBUTIONS}

MCB, CSLV and AC conceptualized the study design; MCB, SH, RCR, RR, RR and SCD carried out formal analysis and investigation; MCB, DVR and CSLV prepared the original draft; MCB, SH, RCR, RR, DVR, RR, SCD, $\mathrm{AC}$ and CSLV reviewed and edited the manuscript; $\mathrm{MCB}$ supervisioned the work.

\section{CONFLICT OF INTERESTS}

None.

\section{REFERENCES}

1. European Food Safety Authority, European Centre for Disease Prevention and Control. The European Union summary report on trends and sources of zoonoses, zoonotic agents and foodborne outbreaks in 2017. EFSA J. 2018;16:5500.

2. Tack DM, Ray L, Griffin PM, Cieslak PR, Dunn J, Rissman T, et al. Preliminary incidence and trends of infections with pathogens transmitted commonly through food - Foodborne Diseases Active Surveillance Network, 10 U.S. sites, 2016-2019. MMWR Morb Mortal Wkly Rep. 2020;69:509-14.

3. Silva WC, Targino BN, Mendonça RS, Sant'Ana AS, Hungaro HM. Campylobacter: an overview of cases, occurrence in food, contamination sources and antimicrobial resistance in Brazil. Food Rev Int. 2018;34:364-89.

4. Silva DT, Tejada TS, Blum-Menezes D, Dias PA, Timm CD. Campylobacter species isolated from poultry and humans, and their analysis using PFGE in southern Brazil. Int J Food Microbiol. 2016;217:189-94.

5. Brasil. Ministério da Saúde. Doenças transmitidas por alimentos: causas, sintomas, tratamento e prevenção. [cited 2020 Oct 29]. Available from: https://antigo.saude.gov.br/saude-de-a-z/ doencas-transmitidas-por-alimentos

6. Brasil. Ministério da Saúde. Secretaria de Vigilância em Saúde. Departamento de Vigilância das Doenças Transmissíveis. Coordenação Geral de Doenças Transmissíveis. Surtos de doenças transmitidas por alimentos no Brasil: informe 2018. Brasília: Ministério da Saúde; 2019. [cited 2020 Oct 29]. Available from: https://portalarquivos2.saude.gov.br/ images/pdf/2019/fevereiro/15/Apresenta----o-Surtos-DTA---
Fevereiro-2019.pdf

7. Downes FP, Ito K, editors. Compendium of methods for the microbiological examination of foods. $4^{\text {th }}$ ed. Washington: APHA; 2001.

8. Brasil. Ministério da Saúde. Agência Nacional de Vigilância em Saúde. Resolução - RDC nº 12, de 2 de janeiro de 2001. Aprovar o regulamento técnico sobre padrões microbiológicos para alimentos. Diário Oficial da União, Brasília, 10 jan. 2001. [cited 2020 Oct 29]. Available from: http://portal.anvisa.gov. br/documents/33880/2568070/RDC_12_2001.pdf/15ffddf63767-4527-bfac-740a0400829b

9. International Organization for Standardization. ISO 102721:2006: microbiology of food and animal feeding stuffs: horizontal method for detection and enumeration of thermotolerant Campylobacter spp.: part 1: detection method. Geneva: ISO; 2006.

10. Kaakoush NO, Castaño-Rodríguez N, Mitchell HM, Man SM. Global epidemiology of Campylobacter infection. Clin Microbiol Rev. 2015;28:687-720.

11. Centers for Disease Control and Prevention. Surveillance for foodborne disease outbreaks, United States, 2017: annual report. Atlanta: CDC; 2019.

12. Rosenquist H, Nielsen NL, Sommer HM, Nørrung B, Christensen BB. Quantitative risk assessment of human campylobacteriosis associated with thermophilic Campylobacter species in chickens. Int J Food Microbiol. 2003;83:87-103.

13. Oh E, McMullen L, Jeon B. Impact of oxidative stress defense on bacterial survival and morphological change in Campylobacter jejuni under aerobic conditions. Front Microbiol. 2015;6:295.

14. Chaveerach P, ter Huurne AA, Lipman LJ, van Knapen F. Survival and resuscitation of ten strains of Campylobacter jejuni and Campylobacter coli under acid conditions. Appl Environ Microbiol. 2003;69:711-4.

15. Chaisowwong W, Kusumoto A, Hashimoto M, Harada T, Maklon K, Kawamoto K. Physiological characterization of Campylobacter jejuni under cold stresses conditions: its potential for public threat. J Vet Med Sci. 2012;74:43-50.

16. Meyer B. Does microbial resistance to biocides create a hazard to food hygiene? Int J Food Microbiol. 2006;112:275-9.

17. Baffone W, Casaroli A, Citterio B, Pierfelici L, Campana R, Vittoria E, et al. Campylobacter jejuni loss of culturability in aqueous microcosms and ability to resuscitate in a mouse model. Int J Food Microbiol. 2006;107:83-91.

18. Li L, Mendis N, Trigui H, Oliver JD, Faucher SP. The importance of the viable but non-culturable state in human bacterial pathogens. Front Microbiol. 2014;5:258.

19. Ayrapetyan M, Oliver JD. The viable but non-culturable state and its relevance in food safety. Curr Opin Food Sci. 2016;8:127-33.

20. Finger JA, Baroni WS, Maffei DF, Bastos DH, Pinto UM. Overview of foodborne disease outbreaks in Brazil from 2000 to 2018. Foods 2019;8:434. 